\title{
OrganizaÇão Virtual E \\ TECNOLOGIA da InFORMAÇÃo
}

\author{
Carlos Baldessarini Cano* \\ Joáo Luiz Becker"* \\ Henrique Mello Rodrigues***
}

\section{Introdução}

$H$ á um certo tempo o termo organização virtual (OV) vem ganhando manchetes na mídia (Mahlmeister, 1995; Oliveira, 1995; Leiria, 1996; Mottin, 1996) e mesmo alguma atenção por parte de teóricos no campo da Administração (Davidow e Malone, 1993; Byrne e Brandt, 1993; Bjur e Caravantes, 1994; Davenport, 1995). O conceito, ainda não consolidado plenamente, engloba diferentes interpretaçōes, desde simples processos de terceirização de atividades (Ridout, 1997) até a adoção de formas de trabalho à distância, comumente rotuladas de tele-trabalho (Skyrme, 1995; Thompson,1997). Mas é inegável que a idéia de virtualização das organizações está intimamente associada à emergência da tecnologia da informação (TI), apontada por alguns como a terceira revolução industrial.

O presente trabalho pretende ser uma contribuição para a construção de uma teoria capaz de explicar a estruturação da OV e delinear o seu papel no cenário empresarial contemporâneo, dentro de uma sociedade em mudança. Em primeiro lugar, é necessário definir o que é aqui entendi-

- Doutorando do Programa de Pós-Graduação emAdministração, Escola de Administração.UFRGS

"* $\mathrm{PhD}$ in Management, University of California, Los Angeles Graduate School of Management "**Pós-doutoramento em Sistemas de Informação pela University of Baltimore, MD, EUA 
do como OV, e como esta localiza-se no cenário das formas emergentes de organização e estruturação empresarial. Tal esclarecimento se faz necessário porque o termo OV, conforme já destacado, tem sido largamente usado de forma ampla e extremamente abrangente.

Nosso objeto de estudo não diz respeito a organizações que simplesmente terceirizaram parte de suas atividades ou adotaram formas de trabatho à distância. Nossa preocupação centra-se no processo de redefinição de atividades, operações e funções administrativas, tornado possível graças ao uso intensivo da TI (Konsynski, 1993).

A informação, em si, é um conceito abstrato. Ela é concretamente percebida e utilizada usando-se convenientes representações e formas de armazenamento. Tomem-se alguns exemplos: pode-se ver um livro como uma particular forma de representar e armazenar as idéias de seu autor (informação nele contida); um cheque pode ser visto como uma particular forma de representar e armazenar a autorização ao banco para pagar determinada quantia a seu portador, debitando convenientemente a conta corrente de seu emitente (informação nele contida). Com o uso cada vez mais acentuado da TI, velhas formas de representação e armazenamento têm sido substituídas por novas formas (com a manutenção da essência), que, quando comparadas diretamente com as substituídas, são quase imperceptíveis, quase invisíveis, dando a impressão de que aquelas foram "virtualizadas". Fala-se no livro virtual e no cheque virtual.

Parece claro que este processo se faz mais contundente em setores econômicos cujos produtos e serviços possuem um conteúdo informacional mais elevado. Entretanto, as conseqüências são percebidas em toda a atividade econômica. A indústria de papel é integralmente afetada pelo processo de virtualização de livros e jornais. Por outro lado, quase toda atividade administrativa, de qualquer organização, em qualquer ramo de atividade, é, em sua essência, informacional, e, portanto, potencialmente virtualizável.

A atenção deste trabalho centra-se na organização (virtual) em um sentido abstrato, nos moldes utilizados por Mota e Pereira (1981), e não exatamente em uma particular organização. Não obstante, os exemplos ilustrativos utilizados, necessariamente concretos, se referem geralmente àquelas organizaçōes que, no todo ou em parte, atingindo um alto grau de virtualização de seu produto ou processo, virtualizaram grande parte do trabalho humano, que convencionalmente formava a base de seus proces- 
sos produtivos e administrativos. Este é o caso da Lufthansa, que está engajada no processo de virtualização de venda de passagens, inclusive do próprio bilhete (http://www.lufthansa.com) ou da Varig, que efetua a venda de assentos via Internet (http://www.varig.com.br). Outros exemplos referem-se às organizações que já surgiram altamente virtuais, sem existirem anteriormente estruturadas de maneira convencional, como é o caso da organização Amazon Books (http://www.amazon.com).

O trabalho está organizado da seguinte forma: na próxima seção apresentam-se os níveis de configuração estrutural e sua relação com a TI; a seguinte focaliza diversos conceitos de OV que têm surgido na literatura, procurando conectá-los; a seção 4 apresenta o conceito de dimensões da virtualização das organizações; na seção 5 exploram-se os conceitos de virtuosidade, busca da essência e confiança e sua conexão; finalmente, a seção 6 conclui o artigo, apresentando nosso conceito de OV.

\section{Níveis de Configuração Estrutural e TI}

A estruturação virtual foi tornada possível pela convergência das indústrias de computadores e de comunicação. Tal convergência viabilizou a criação de uma infra-estrutura de informação que tem sido genericamente chamada de supervias de informação (do inglês "information superhighway"). Trata-se de redes de comunicação de banda larga, de abrangência global, que, com eficiência, transmitem dados, voz, imagens (estáticas ou em movimento), em "real-time" e com interatividade. Devido à elevada performance obtida, com custos praticamente nulos, tais supervias estão sendo usadas em grande escala, em crescimento acentuado, tanto em número de usuários ativos quanto em volume de informações transportadas, sem que este crescimento tenha, até o momento, apresentado sinais de arrefecimento. Este uso intenso e contínuo, de forma barata, eqüivale à queda de limites antes impostos pelos parâmetros de distância de deslocamento e tempo de transporte. Assim, pode-se desconsiderar tempo e distância no transporte de informações.

Somente a derrubada dos limites de distância e tempo já seriam suficientes para alterar profundamente a forma de estruturar aquelas organizaçôes que possam se valer do uso intenso das supervias de comunicação e 
usufruir dos conseqüentes benefícios. Porém, outras características dessas supervias são também marcantes, importantes pelas possibilidades operacionais inovadoras que trazem para as organizações, quando usadas de forma isolada ou combinadas: linguagens padronizadas, baixo custo de aces so, modularidade do transporte dos blocos de informação, boas condições de segurança quanto à integridade e sigilo das informações, etc.

Tais supervias podem ser abstratamente entendidas como espaços, onde representações desempenham as funções das organizações que as criaram, interagindo de forma a produzir resultados previsíveis, como se fossem agentes físicos (possivelmente humanos eficazes e produtivos). Estes espaços de interação e de trocas, chamados de espaços cibernéticos, ou ciberespaços (Gibson, 1984, 1997; Bauwens, 1993; Josefson, 1994; Almeida et alii, 1995; Pesce, 1995, 1998; Benedikt, 1996; Park, 1996), possibilitaram o surgimento de organizações cujas estruturas apresentam diversos aspectos virtualizados, quando comparadas com estruturas convencionais de objetivos e portes assemelhados.

Venkatraman (apud SDrensen, 1997) aponta uma hierarquia de formas organizacionais baseadas em cinco níveis de reconfiguração estrutural, possibilitadas pelo uso, com maior ou menor intensidade, da TI. Na Figura 1 apresenta-se esta hierarquia.

Estes níveis hierárquicos não representam necessariamente uma linha evolutiva, sendo configurações com diferentes intensidades de uso da TI. Diferentes níveis podem estar presentes simultaneamente num mesmo cenário organizacional. No entanto, é importante notar que somente quando a configuração estrutural for adequada ao nível e formato da TI utilizada é possível usufruir da totalidade dos benefícios esperados num determinado estágio de informatização.

Os dois primeiros níveis estão no patamar evolucionário do uso da informatização, enquanto que os demais estão num patamar que Venkatraman chama de revolucionário. Os primeiros (evolucionários), mantêm a estruturação básica da organização e esta define a aplicação da TI que lhe é mais conveniente, em sua forma e intensidade. Nos demais estágios (revolucionários), ao contrário, o nível de informatização e comunicação utilizados definem a forma de estruturar a organização.

Os níveis evolucionários estão suficientemente estudados e já fazem parte do que pode ser chamado de Administração Convencional. No en- 


\section{Figura 1: Transformações Organizacionais Possibilitadas pela TI}

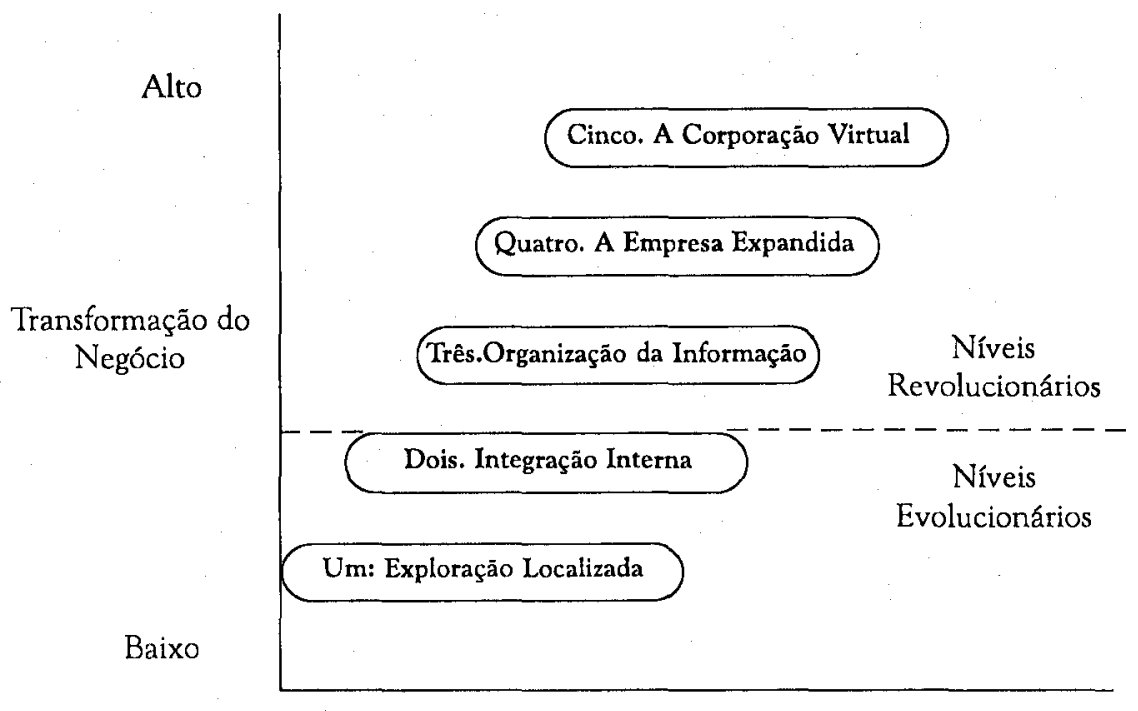

Amplitude dos Benefícios Potenciais

Fonte: Venkatraman (apud SArensen, 1997, p.3)

tanto, os três níveis revolucionários são negócios induzidos pela exploração e aproveitamento intensivo da TI, que possibilitam o rompimento de barreiras e dos parâmetros de limitaçōes que tradicionalmente guiaram as estruturações organizacionais convencionais. Essas rupturas podem ser consolidadas, com maior ou menor intensidade, em torno de métodos que objetivam virtualizar fases ou componentes dos métodos produtivos e administrativos responsáveis pela operação e operacionalidade da organização, sua competitividade e sua sobrevivência no mercado.

O presente trabalho busca focar e analisar o último estágio, que Venkatraman chama de corporação virtual. E, dentro deste estágio, busca um foco ainda mais fino, dirigido à organização que, graças a técnicas recentemente desenvolvidas, virtualiza não só seu produto, mas também, em grande parte, o trabalho humano e seus processos produtivos e administrativos, ou seja, em sua operação. Atendem, satisfazem e encantam seus clientes, a partir de estruturas organizacionais praticamente despojadas de mão-de-obra humana. 


\section{Um Conceito em Construção}

O conceito de OV ainda não se consolidou. Sègundo Sieber (1997), a expressão $\mathrm{OV}$ se refere a uma organização que acessa conhecimentos e recursos externos, por vezes geograficamente dispersos, que podem representar o produto de seres humanos, de outras corporações (tradicionais ou virtuais), de bancos de dados, sistemas ou qualquer outra entidade que possa contribuir para a agregação de valor à sua cadeia produtiva. Como qualquer organização, a OV fornece bens ou serviços, buscando atingir o máximo de eficácia e de agregação de valores em seu processo operacional e administrativo.

Preferimos o conceito oferecido por Mowshowitz (1997), que tem servido de referência para outros estudos sobre o tema (Faucheux, 1997; Turoff, 1997).

Mowshowitz (1997), parte da separação das demandas (representadas por seus requisitos abstratos) e das possíveis entidades que satisfarão estas demandas, separação esta que gera a necessidade de quatro atividades administrativas básicas:

- formulação das necessidades abstratas, representativas das demandas apresentadas;

- procura e análise de entidades (concretas) capazes de satisfazer as necessidades abstratas;

- alocação dinâmica destas entidades aos demandantes, segundo critérios específicos;

- investigação e análise dos critérios de alocação, com vistas à sua avaliação frente aos objetivos e metas da organização.

Na matriz de combinações possíveis entre entidades demandantes e entidades que satisfazem as necessidades abstratas demandadas, tanto as solicitações de serviços ou produtos como também os supridores de soluções podem variar dinamicamente com o passar do tempo. Também podem variar os critérios que direcionam uma demanda específica ao atendente mais adequado. Portanto, passa a ser uma tarefa continuada da administração a prospecção de novas combinações de recursos e de critérios de alocação. Dentro deste quadro, é necessário que a organização reconheça 
explicitamente a solução do problema de conectar as entidades que demandam com as que potencialmente satisfarão esta demanda.

Salientamos que as quatro atividades administrativas básicas mencionadas, como toda e qualquer atividade administrativa, são essencialmente informacionais. De fato, a essência da definição de Mowshowitz é a separação entre necessidades abstratas (informação) e satisfatores concretos (produtos). A OV atua no espaço informacional.

Ao reconhecer explicitamente a distinção entre os requisitos funcionais da demanda e os meios que a satisfarão, abre-se um campo de exploração que busca encontrar novos meios de satisfazer antigas demandas, mantendo a essência, que chamamos processo de virtualização. Por exemplo, se a demanda é gerada por jogadores que querem apostar em um cassino, uma forma convencional seria levá-los fisicamente a um cassino, onde encontrariam equipamentos de jogos e uma equipe para conduzir as appostas. A TI disponível hoje permite que o cassino (virtual) seja levado ao jogador (demandante) e assim atender suficientemente o anseio que propiciou a transação. Claro está que aquele jogador que julga importante as luzes, a música, o brilho e o charme de um cassino convencional, poderá não se satisfazer com a solução proposta. Mas outros se sentirão satisfeitos, a ponto de aceitar o serviço. Muitos de nós preferimos o contato, o cheiro, a presença física de um livro, mas uma visão objetiva pode nos levar a aceitar o livro virtual, via biblioteca virtual, como uma fonte suficientemente eficaz de conhecimento.

Assim, tanto quanto prospectar entidades capazes de satisfazer as necessidades de seus clientes (definidas em termos abstratos), cabe à administração da OV investigar quais os possíveis meios concretos de satisfazê-las, mesmo que isto represente uma alteração de hábitos ou mesmo de cultura.

Os espaços cibernéticos têm facilitado a criação e aceitação de novos meios de satisfazer antigas necessidades, bem como de gerar necessidades novas para serem atendidas por novas formas de serviços. Na primeira categoria (novos meios de atender necessidades existentes), os exemplos são abundantes: a biblioteca virtual, o cassino virtual, o museu virtual, o "e-mail", etc. Na segunda (geração de novas necessidades) encontram-se a pesquisa global através dos "browsers" (como o http:// www.altavista.digital.com), a crescente exigência de visualização gráfica, o tele-trabalho, etc. Além disto, os espaços cibernéticos têm permitido o 
refinamento de requisitos de necessidades já existentes, de tal forma que parecem novas necessidades, como o produto personalizado ao alcance da massa consumidora (calças, carros, livros pessoais, etc.). Já é possível a adoção de estratégias mercadológicas inéditas, como a atomização (nicho de um só) em massa. É inegável que a substituição dos meios físicos de satisfação de necessidades abstratas por meios virtuais pode ser sentida em toda a vida moderna, em todas as camadas da população.

Um visão semelhante de OV é apresentada por Zimmermann (1997), preferindo usar a expressão empreendimento virtual ("virtual enterprise"). O autor usa o termo virtual para designar o que é suficientemente semelhante a algo, embora lhe falte alguns atributos significativos. ${ }^{1}$ Zimmermann (1997) aponta os exemplos da realidade virtual e de produtos virtuais, que não possuem estruturas físicas, só existindo de fato nos computadores. Para o observador, a realidade ou o produto "existe na mente, especificamente como produto da imaginação" (segundo o mesmo autor, definição extraída do American Heritage Dictionary). De acordo com esta definição, resulta ser o empreendimento virtual um empreendimento que deixa de ter algumas caracterís ticas estruturais dos empreendimentos reais, embora funcione como um empreendimento na imaginação do observador.

Zimmermann (1997) explica o conceito de empreendimento virtual usando o exemplo da arquitetura da memória nos computadores, onde não é econômico instalar bancos de memória suficientemente grandes para atender todas as demandas possíveis, geradas por qualquer programa que venha a ser usado. A solução tem sido o uso de uma memória principal de tamanho ótimo e memórias secundárias de extensão ilimitada. Através da alocação dinâmica da memória real e das secundárias, é possível atender a programas que demandem grandes espaços de armazenamento, bem como programas que devem ser trabalhados simultaneamente. Ou seja, sob a ótica de Mowshowitz (1997), alocam-se entidades (memória principal e secundárias) dinâmica e flexivelmente para atendimento de demandas abstratas de desempenho (programas).

Segundo Zimmermann (1997), uma OV, como empreendimento em rede, pertence ao grupo dos sistemas de negócios que podem ter 
suas estruturas decompostas em subsistemas de administração e subsistemas de serviços. Os sistemas de administração planejam e controlam os sistemas de serviços da organização, buscando atender a:

- funções de pesquisa e informação, definindo como a OV busca seus clientes, como estrutura seu marketing e como identifica seus fornecedores ou parceiros;

- funções de contratação, regulando a negociação com seus clientes, fornecedores e parceiros, e

- funções de operação e suporte, definindo as matrizes de combinação dos diferentes serviços que são ofertados, como são ofertados aos clientes, e dando suporte contábil e fiscal à organização.

\section{Figura 2: Conceito de Empreendimento Virtual}

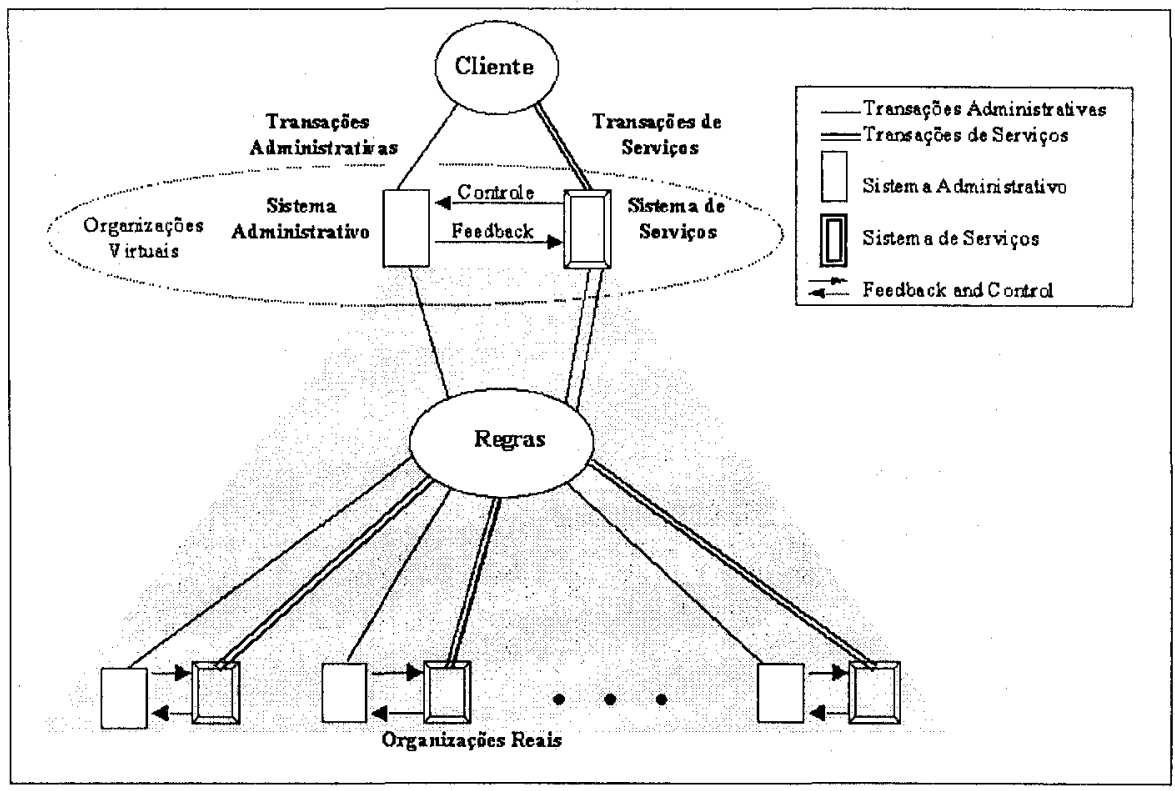

Fonte: Adaptado de Zimmermann (1997, p.5)

Na Figura 2 sintetiza-se a concepção que Zimmermann (1997) apresenta da estruturação da OV, salientando a linha de ação dos sistemas ad- 
ministrativos e de serviços, as regras de alocação de recursos e de acionamento de clientes, fornecedores e parceiros (a conjugação dos sistemas administrativos e de serviços funciona como um sistema de negócios, dotado de controle e feedback. Na organização virtual, o sistema administrativo pode existir independente da existência de um órgão central de administração, pois pode ser formado pelo conjunto de regras contidas nos sistemas de serviço. As regras referem-se principalmente a três aspectos funcionais da organização: pesquisa e informação, contração e operação com o apoio necessário).

A evolução de uma organização convencional para uma OV não é um processo rápido (Sieber, 1997). Os motivos para a evolução são vários: redução de complexidade, maior flexibilidade de resposta, desenvolvimento em novas áreas geográficas ou novos segmentos de mercados, redução da incerteza, etc. Um processo de virtualização, segundo Arnold et alii (apud Sieber, 1997), pode ser representado por uma mudança estrutural em cinco estágios, conforme detalhado na Figura 3.

\section{Figura 3: Estágios de Evolução para uma OV}

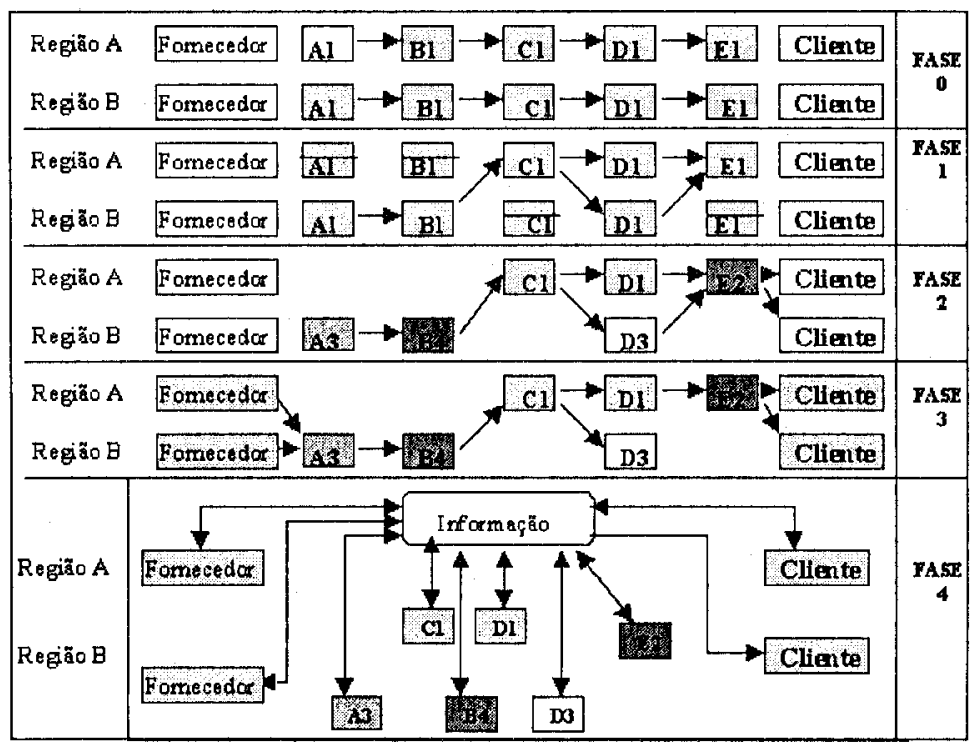

Fonte: Arnold et alii (apud Sieber, 1997, p.3) 
O diagrama apresenta um exemplo fictício de uma organização que passa gradualmente pelo processo de virtualização. $\mathrm{Na}$ fase zero a organização se apresenta verticalmente integrada, convencionalmente estruturada, com várias unidades de negócios duplicadas, geograficamente distribuídas.

$\mathrm{Na}$ fase 1 , inicia-se o processo de virtualização, com a produção total sendo concentrada em um só local. Para manter a mesma eficácia, é necessário fortalecer os fluxos informacionais entre as unidades de negócios.

$\mathrm{Na}$ fase 2, uma rede de companhias é formada para suprir os bens ofertados ao mercado. Neste estágio já é necessário um sistema de informação razoavelmente sofisticado entre as companhias.

A fase 3 inicia quando fornecedores e clientes săo integrados ao sistema, participando ativamente do processo (McKinney e Gerloff, 1997). Nesta fase os sistemas de informações tornam-se fatores decisivos de sucesso, pois o fluxo computadorizado de informação passa a assumir funções antes desempenhadas por setores físicos dentro da burocracia hierárquica convencional (Riggins e Rhee, 1997). Uma organização nesta fase também é chamada de companhia em rede, ("Network Company"). Esta fase representa uma transição importante e arriscada para a organização, pois esta pode decidir, ao continuar sua evolução, assumir a função de coordenação das atividades de uma rede de outras entidades, ficando numa posição de intermediário no mercado ("Information Broker"), ingressando na fase 4. O risco está em, ao ingressar na fase 4 de seu processo de virtualização, a organização abandonar suas competências específicas, não mais conseguindo uma diferenciação no mercado.

Sieber (1997) aponta o exemplo da Microsoft, que delegou a terceiros sua produção, suas vendas, marketing e distribuição, reservando para si o desenvolvimento de produtos. Mantendo controle de sua competência principal, consegue preservar uma posição dominante no mercado. Também a indústria automotiva tem seguido um modelo semelhante de virtualização, ao delegar várias de suas funções administrativas e produtivas, mas reservando para si aquela que é seu diferencial de mercado: a concepção de produtos.

Este modelo de virtualização tem sido o caminho seguido pelas empresas maiores. Já as organizaçôes pequenas e médias tentam saltar imediatamente para a fase 4 , ou mesmo já surgem com características virtuais. 


\section{Dimensões da Virtualidade}

Venkatramam (apud Sieber, 1997) sugere um enfoque funcional e estratégico para a evolução do processo de virtualização, em busca de eficiência em três áreas básicas da organização: recursos, mercado e processo, conforme ilustrado na Figura 4.

\section{Figura 4: OV em Três Dimensóes e Três Estágios}

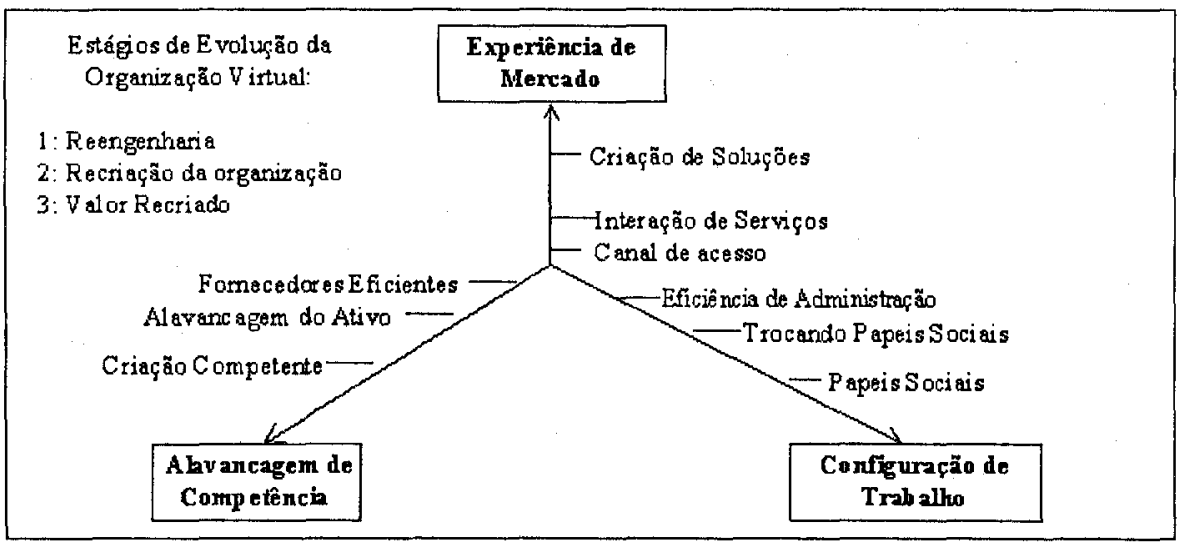

Fonte: Venkatraman (apud Sieber, 1997, p.4)

Na área de mercado, o processo de virtualização busca a otimização da satisfação dos clientes, via envolvimento destes no processo de definição dos produtos ou serviços. No primeiro estágio (canal de acesso), os clientes são ligados à organização por um canal de comunicação, com o qual os setores envolvidos no atendimento podem mais eficientemente comunicar-se com eles. No segundo estágio (interação de serviços), uma posição pró-ativa no desenvolvimento de produtos e serviços é possível de ser atingida. No terceiro estágio (criação de soluções), o cliente torna-se um parceiro na solução de problemas, adicionando seu conhecimento específico ao processo de criação e produção. O objetivo é passar do estágio de retroalimentação das informações, na pesquisa de mercado e desenvolvimento de produto, para um ativo envolvimento do cliente no processo, na criação de soluções e adequação de atendimento. Assim, a organização 
virtualizada torna-se o lugar onde os conhecimentos específicos são reunidos na tentativa de construir o melhor processo, pela adição de valores considerados importantes.

$\mathrm{Na}$ área de competência, o processo de virtualização inicia no primeiro estágio com a redefinição de suas fontes de recursos, abrindo um horizonte largo de possíveis fornecedores de matérias primas, produtos semiacabados e competências estratégicas. No segundo estágio, vínculos estratégicos são estabelecidos, através de cooperação, contratos de fornecimento a longo prazo ou associações, buscando bases flexíveis para a manutenção do processo produtivo. Por exemplo, alianças com fornecedores de insumos "zero erro", incorporáveis de imediato à produção, dispensando a estocagem e o controle de qualidade de ingresso, podem ser estabelecidas. No terceiro estágio, funções são trocadas entre a organização, fornecedores, clientes ou parceiros. As fronteiras entre companhias são redefinidas ou tornadas mais permeáveis: tanto o fornecedor pode assumir funções internas do cliente (controle de estoque num acordo de reposição contínua, por exemplo), como o cliente pode assumir funções antes específicas do fornecedor (desenvolvimento conceitual do produto, por exemplo).

A troca de funçōes entre a $O V$, clientes, fornecedores e parceiros pode implicar em:

- aquisição de novos conhecimentos pelas entidades envolvidas;

- eliminação de funçóes duplicadas nas entidades envolvidas, e

- junção de esforços e conhecimentos, com a criação de novas entidades.

Em função da multiplicidade de associações livres, as organizaçōes envolvidas no processo de produção de bens e serviços podem ser parceiras numa área e competirem em outra.

No eixo da configuração de trabalho, a virtualização começa com o reexame do processo, em busca de eficiência, que pode se dar por:

- reengenharia dos processos produtivos, buscando formas mais eficientes de disponibilizar produtos ou serviços, e

- prospecção ou criação de novas formas de atender as demandas, via novos produtos ou serviços. 
O segundo estágio (troca de parâmetros sociais), inicia quando a organização descentraliza suas decisões através da abertura das informações aos funcionários, que passam a decidir de forma crescentemente autônoma. Como conseqüência, preparam-se as bases para o terceiro estágio, que consiste na criação de unidades autônomas de trabalho dentro da organização. Com a multiplicação das unidades autônomas de trabalho, pode-se atingir a situação em que cada funcionário funciona como especialista autônomo. Uma rede de conhecimentos autônomos substitui o sistema hierárquico, antes usual, provocando uma redefinição dos papéis sociais na organização.

\section{Virtuosidade, Essencialismo e Confiança}

O conceito de OV estaria incompleto se não fosse relacionado a um outro termo derivado de virtus: a virtuosidade (Reinermann, 1996). A virtuosidade significa a perfeição, o completo domínio da arte de bem fazer, alta qualidade, excelência. Para atingir a virtuosidade, a OV deve considerar também os fatores humanos, culturais e individuais, importantes para a plena satisfação de seus clientes. A TI permite a eficácia da OV, mas só a sensibilidade de seus administradores pode conduzíla à virtuosidade.

Uma OV é essencialista por natureza, no sentido de que busca a essência de sua razão de ser, identificando quais são as necessidades abstratas de seus clientes, atuais ou potenciais. Ao identificar tais necessidades abstratas, procura associá-las a satisfatores, dentro de um regramento estratégicamente estabelecido. Presta o serviço de alocar, dinamicamente, necessidades e satisfatores, dentro de uma visão de otimização do processo.

Uma OV é uma organização baseada em confiança (Handy, 1995). De fato, para bem funcionar, a OV necessita confiar em seus processos, assim como deve inspirar plena confiança em sua clientela, fornecedores e demais parceiros. Tanto do lado tecnológico como do lado humano, sua representação deve ser isenta de erros e imprecisões. Qualquer falha pode levar a conseqüências desastrosas para a organização.

Este três conceitos não são desconexos.

A OV pode ir mais longe na busca da essência de sua razão de ser, ao investigar possíveis novas formas de satisfazer as necessidades de seus clientes. O processo de substituição de satisfatores físicos tradicionais por 
representações que os virtualizam, é, na verdade, um processo de busca da virtude básica, de virtuosidade, que irá produzir o efeito desejado, a satisfação da necessidade abstrata. Por outro lado, a OV volta-se para o seu interior com o mesmo questionamento da busca da essência de seus processos administrativos e de serviços, buscando a virtualização de seus recursos e procedimentos. Esta contínua busca da essência, da virtude que produz o efeito desejado, da virtuosidade do bem feito, tende a fortalecer o clima de confiança fundamental para o relacionamento com seus clientes, fornecedores e parceiros, tornando-o duradouro.

\section{Conclusão: afinal o que é OV?}

Percebemos que o conceito de OV não representa unanimidade entre os estudiosos. Ao longo deste trabalho procuramos resgatar diversos conceitos e idéias subjacentes ao tema, permitindo-nos, ao final, apresentar, em síntese, nossa definição de OV.

Uma OV é um arranjo sistêmico de entidades - homens, agentes autônomos, organizações (virtuais ou não), sistemas, bancos de dados, transdutores que busca interligar e integrar dinamicamente, por meio de Tl, demandas e recursos para sua satisfação, com regras de atuação estrategicamente definidas.

Uma OV cria uma matriz organizacional, polidimensional, que interliga e integra dinamicamente demandas, recursos e regras de atuação, de forma precisa e confiável. As funções administrativas e de serviços são desempenhadas por humanos e por agentes não humanos, como outras organizações, bancos de dados, sistemas, programas transdutores, etc. São usados os recursos informacionais mais diversos, tornados possíveis pela convergência tecnológica das indústrias de computação, telecomunicações e de realidade virtual. A OV busca a virtuosidade, a excelência, e o faz buscando a essência de sua razão de ser, de seus processos e procedimentos, a virtude de provocar os efeitos desejados, procurando dissociar as necessidades abstratas de seus satisfatores físicos tradicionais, bem como de suas cadeias usuais de distribuição. A OV estrutura-se embasada em confiança, tanto em seus sistemas e processos, como no relacionamento com seus clientes, fornecedores e parceiros. Devido ao uso intenso de TI, tem suas fronteiras pouco definidas, explorando esta fraca definição para exteriorizar 
aquilo que contém em seus domínios, bem como para internalizar o que está fora de seus domínios.

É importante ressaltar, que não existe uma organização totalmente virtualizada, pois sempre haverá uma base tecnológica concreta que lhe dê suporte. Pensar idealmente em uma organização virtual pura é, entretanto, interessante sob o ponto de vista de análise. Esta organização ideal seria de todo semelhante ao que hoje conhecemos como vírus de computador ou um jogo em computador: são entidades autônomas que, uma vez geradas e libertas no espaço cibernético, multiplicam-se e perpetuam-se continuamente, produzindo resultados sem necessidade de intervenção humana adicional.

Do ponto de vista prático, há notícias de organizações que se aproximam do modelo ideal. Por exemplo, um formando da Escola de Administração da Universidade Federal do Rio Grande do Sul, funcionário em período integral de um Banco, num projeto de Prática Profissional, "programou", nos finais de semana, uma organização bastante virtualizada, cuja razão operacional é a revenda de CDs musicais. Esta organização programada, tornou-se uma empresa, a Import Laser, (http:// www.importlaser.com.br), em atividade, 24 horas por dia, 7 dias por semana, que disponibiliza, para um grupo de clientes previamente cadastrados (via Internet), lançamentos e coleções de CDs nacionais e estrangeiros. Os pedidos dos clientes são repassados aos fornecedores que providenciam a entrega. A operação é encerrada quando os respectivos pagamentos são realizados. Tudo com alto grau de informatização e usando técnicas atuais de Administração, como a exploração de nichos atomizados de mercado (Shewe e Smith, 1980). Hoje, este profissional continua sendo funcionário do Banco, enquanto sua empresa mantém representação ativa no ciberespaço, produzindo bons resultados concretos, desde o início de suas atividades. Resultados operacionais positivos foram obtidos desde o início das operações graças ao baixo ponto de equilíbrio, provocado pelos baixos custos fixos, no caso uma hospedagem de $\mathrm{R} \$ 200,00$ mensais em um provedor de Internet.

Outro exemplo digno de nota é o cassino virtual (http:// www.casinoconection.com, http://www.starluck.com, http://www. worldgaming.com, http://www.atlantis-gaming.com) já mencionado, onde apostadores podem ingressar (virtualmente) em uma representa- 
ção de um cassino, escolher o jogo que gostam de jogar, apostar e, é claro, perder ou ganhar.

Este novo cenário que está sendo construído de forma autônoma permite o emprego de modelos e metáforas antes impossíveis de serem implantados. A reinterpretação de visōes administrativas, à luz das novas possibilidades, inéditas, que estão sendo usadas nos alicerces das estruturas das organizações virtuais é imperativo.

Notas

${ }^{1}$ Etimologicamente a expressão virtual vem do latim virtus, significando excelência moral.

\section{Referências Bibliográficas}

ALMEIDA, A.S.P.S.; L.G. ROQUE e A.D. FIGUEIREDO (1995). "Cyberspace: an architecture". http://mimosa.dei.uc.pt/ asa/Papers/ Cyberspace2.

BAUWENS, M. (1993). "Cyberspace, virtualization, and the role of cybrarians". Space.txt. http://www.ecom .be/space.

BENEDIKT, M. (1996). "Cyberspace: some proposals". Cyberspace. http:virtual.park.uga. edu/ hypertxt/cyberspace.

BJUR, W. e G.R. CARAVANTES (1994). Reengenharia ou Readministração?. Porto Alegre: AGE Editora, 187p.

BYRNE, J.A. e R. BRANDT (1993). "The virtual corporation". Business week. Fev, 8, p.99-103.

DAVENPORT, T. (1995). "The virtual and the physical". CIO Magazin.

Nov. http:www.cio. com./cio/cio_11_15_95_dav.

DAVIDOW, W.H. e MALONE, M.S.S. (1993). $\bar{A}$ Corporação Virtual: São

Paulo: Pioneira, $271 \mathrm{p}$.

HANDY, C. (1995). "Trust and the virtual organization". Harvard Business

Review. Mai-Jun, p.40-45.

FAUCHEUX, C. (1997). "How virtual organizing is transforming management science". Communications of the ACM. Set, 40(9):50-55. GIBSON, W. (1984). Neuromancer, New York; Ace. 
(1997). "The Net is a waste of time - and that's what's right about it". Sundance Film Festival. http:sundance.net/institute/articles/ gibson.html.

JOSEFSON, D. (1994). "Entrevista com W. Gibson". Rapport, Stockholm, sweeden. http:// www.algonet.se\%7edanj/gibson.html.

KONSYNSKI, B.R.(1993). "Strategic control in the extended enterprise". IBM Systems Joumal. 32:1,Mar,p.111-143.

LEIRIA, L. (1996). "O PIB brasileiro chega à internet". Internet World. Mar:48-55.

MAHLMEISTER, A.L. (1995). "As empresas já apostam na era do varejo virtual". Gazeta Mercantil. 31/08,p.6.

McKINNEY, V. e E. GERLOFF (1997). "Interorganizational systems partnership effectiveness". http://hsb.baylor.edu/ramsower/ais.ac.97/ papers/mckin2.htm.

MOTA, F.C.P. e L.C.B. PEREIRA (1981). Introdução à Organização Burocrática, 2.ed. São Paulo: Brasiliense.

MOTTIN, V. (1996). "Banco virtual chega a Porto Alegre". Jornal do Comércio. 12/02,p.14.

MOWSHOWITZ, A. (1997). "Virtual organization". Communications of the ACM. Set, 40(9):30-37.

OLIVEIRA, D. (1995). "O futuro é do mundo virtual". Gazeta mercantil. $19 / 09$.

PARK, B.V. (1996). http://www.flogiston.com/DIKU/3space/3spflow.

PESCE, M. (1995). "The VRML equinox, building on the web". De Architetura. http:// 131.175.64.52/dea/news/events/vp95/proc/ pesce.htm.

(1998) "A brief history of cyberspace". ZDNet. http:// www3.zdnet.com/products/ vrmluser/perspectives/mp.history.html. REINERMANN, H. (1996). "Virtual organizations". Informatika. 1:12-19. http://www.hfv-speyer.de/rei/publica/eng/virorga.htm.

RIDOUT, R. (1997). "The virtual IT Organization". Techweb News. 22/07.

http://www. techweb.com/se/directlink.cgi?IWK19970922s0044.

RIGGINS, FJ. e H. RHEE (1997). "Developing the learning network using extranets". http:// 130.207.57.82/papers/learning.html.

SCHEWE, C.D. e R.M. SMITH (1980). Marketing: concepts and applications. New York: McGraw-Hill, 665p. 
(1997). "The Net is a waste of time - and that's what's right about it". Sundance Film Festival. http:sundance.net/institute/articles/ gibson.html.

JOSEFSON, D. (1994). "Entrevista com W. Gibson". Rapport, Stockholm, sweeden. http:// www.algonet.se\%7edanj/gibson.html.

KONSYNSKI, B.R.(1993). "Strategic control in the extended enterprise". IBM Systems Joumal. 32:1,Mar,p.111-143.

LEIRIA, L. (1996). "O PIB brasileiro chega à internet". Internet World. Mar:48-55.

MAHLMEISTER, A.L. (1995). "As empresas já apostam na era do varejo virtual". Gazeta Mercantil. 31/08,p.6.

McKINNEY, V. e E. GERLOFF (1997). "Interorganizational systems partnership effectiveness". http://hsb.baylor.edu/ramsower/ais.ac.97/ papers/mckin2.htm.

MOTA, F.C.P. e L.C.B. PEREIRA (1981). Introdução à Organização Burocrática, 2.ed. São Paulo: Brasiliense.

MOTTIN, V. (1996). "Banco virtual chega a Porto Alegre". Jornal do Comércio. 12/02,p.14.

MOWSHOWITZ, A. (1997). "Virtual organization". Communications of the ACM. Set, 40(9):30-37.

OLIVEIRA, D. (1995). "O futuro é do mundo virtual". Gazeta mercantil. $19 / 09$.

PARK, B.V. (1996). http://www.flogiston.com/DIKU/3space/3spflow. PESCE, M. (1995). "The VRML equinox, building on the web". De Architetura. http:// 131.175.64.52/dea/news/events/vp95/proc/ pesce.htm.

(1998) "A brief history of cyberspace". ZDNet. http:// www3.zdnet.com/products/ vrmluser/perspectives/mp.history.html. REINERMANN, H. (1996). "Virtual organizations". Informatika. 1:12-19. http://www.hfv-speyer.de/rei/publica/eng/virorga.htm.

RIDOUT, R. (1997). "The virtual IT Organization". Techweb News. 22/07. http://www. techweb.com/se/directlink.cgi?IWK19970922s0044. RIGGINS, F.J. e H. RHEE (1997). "Developing the learning network using extranets". http:// 130.207.57.82/papers/learning.html.

SCHEWE, C.D. e R.M. SMITH (1980). Marketing: concepts and applications. New York: McGraw-Hill, 665p. 
SIEBER, P. (1997). "Virtual organizations: static and dinamic viewpoints". Virtual Organization. http://www.virtual-organization.net/news/nl-1.2/ sieber.html.

SORENSEN, S. (1997). "Towards the new firm". http://www.marktg.cbs.dk/ wais/towafirm.

SKYRME, D. (1995). "The networked organisation". http:// www.skyrme.com/insights/ 1network.htm.

THOMPSON, C. (1997). "Virtual office". Defense Advanced Research Projects Agency, http://www.objs.com/survey/vo.htm.

TUROFF, M. (1997). "Virtuality". Communications of the ACM. Set, 40(9):38-43.

ZIMMERMANN, F.O. (1997). "Structural and managerial aspects of virtual enterprises". Virtuelle Unternehmen. http:// www.seda.sowi.inibamberg.de/persons/zimmermann/paper/estiem.htm. 